\title{
REVIEW
}

\section{Clinical review: The $A B C$ of weaning failure - a structured approach}

\author{
Leo M Heunks* and Johannes G van der Hoeven
}

\begin{abstract}
About 20\% to $30 \%$ of patients are difficult to wean from invasive mechanical ventilation. The pathophysiology of difficult weaning is complex. Accordingly, determining the reason for difficult weaning and subsequently developing a treatment strategy require a dedicated clinician with in-depth knowledge of the pathophysiology of weaning failure. This review presents a structural framework ('ABCDE') for the assessment and treatment of difficult-to-wean patients. Earlier recognition of the underlying causes may expedite weaning from mechanical ventilation.
\end{abstract}

\section{Introduction and focus}

In most patients, mechanical ventilation can be discontinued as soon as the underlying reason for acute respiratory failure has been resolved. However, $20 \%$ to $30 \%$ of patients are considered difficult to wean from mechanical ventilation. Weaning failure is defined as the failure to pass a spontaneous-breathing trial or the need for reintubation within 48 hours following extubation [1]. The risks associated with post-extubation distress and reintubation are considerable. Therefore, clinicians often choose to use a two-step diagnostic approach before extubation. First, weaning parameters are assessed (screening), and, second, a weaning trial is initiated. The validity of the different screening tools (for weaning), such as the rapid shallow breathing index and maximal inspiratory pressure, has been discussed in detail elsewhere [2]. Different techniques have been used for weaning and these include gradual reduction in mandatory rate during intermittent mandatory ventilation, gradual reduction in pressure support, and spontaneous breathing through a T-piece. Esteban and colleagues [3] concluded that trials of spontaneous breathing resulted in

*Correspondence: I.heunks@ic.umcn.n

Department of Intensive Care Medicine (632), Radboud University Nijmegen Medical Centre, Postbox 9101, 6500 HB Nijmegen, The Netherlands faster liberation from mechanical ventilation compared with weaning using pressure support or intermittent mandatory ventilation. However, other studies failed to prove the superiority of spontaneous-breathing trials over pressure support ventilation as a weaning technique $[4,5]$. These differences in outcome most likely are related to the different designs of these studies, patient characteristics, and durations of mechanical ventilation before initiation of weaning. In-depth discussion of weaning techniques is beyond the scope of this paper and has been published earlier [2].

The pathophysiology of weaning failure is complex and often multifactorial. Accordingly, determining the reason and subsequently developing a treatment strategy require a dedicated clinician with in-depth knowledge of the pathophysiology of weaning failure. Several reviews have been published on weaning failure, but most focus on only one aspect of weaning and therefore are of limited help to clinicians. Complex clinical problems probably benefit from a structured approach. An 'ABC approach' is valuable in training juniors in trauma management [6]. In this paper, we present an opinion-based 'ABC approach' for difficult weaning. Unlike the $\mathrm{ABC}$ in trauma medicine ('treat first that kills first'), our 'weaning $A B C$ ' does not emphasize a specific order of assessment but is purely alphabetical and has the advantage of 'forcing' the clinician to systematically review the most likely causes for failed weaning. With the understanding of the barriers that impede successful weaning in a specific patient, a tailored treatment strategy that may reduce duration of mechanical ventilation can be designed. The following topics should be evaluated in a difficult-towean patient (Figure 1): airway and lung dysfunction, brain dysfunction, cardiac dysfunction, diaphragm dysfunction, and endocrine dysfunction. The algorithm presented in Figure 1 shows possible strategies to confirm the role of any of these items and options to reduce the contribution to weaning failure.

\section{Airway and lung dysfunction}

Elevated airway resistance, reduced respiratory system compliance, and impaired gas exchange increase the work of breathing and as such contribute to weaning 


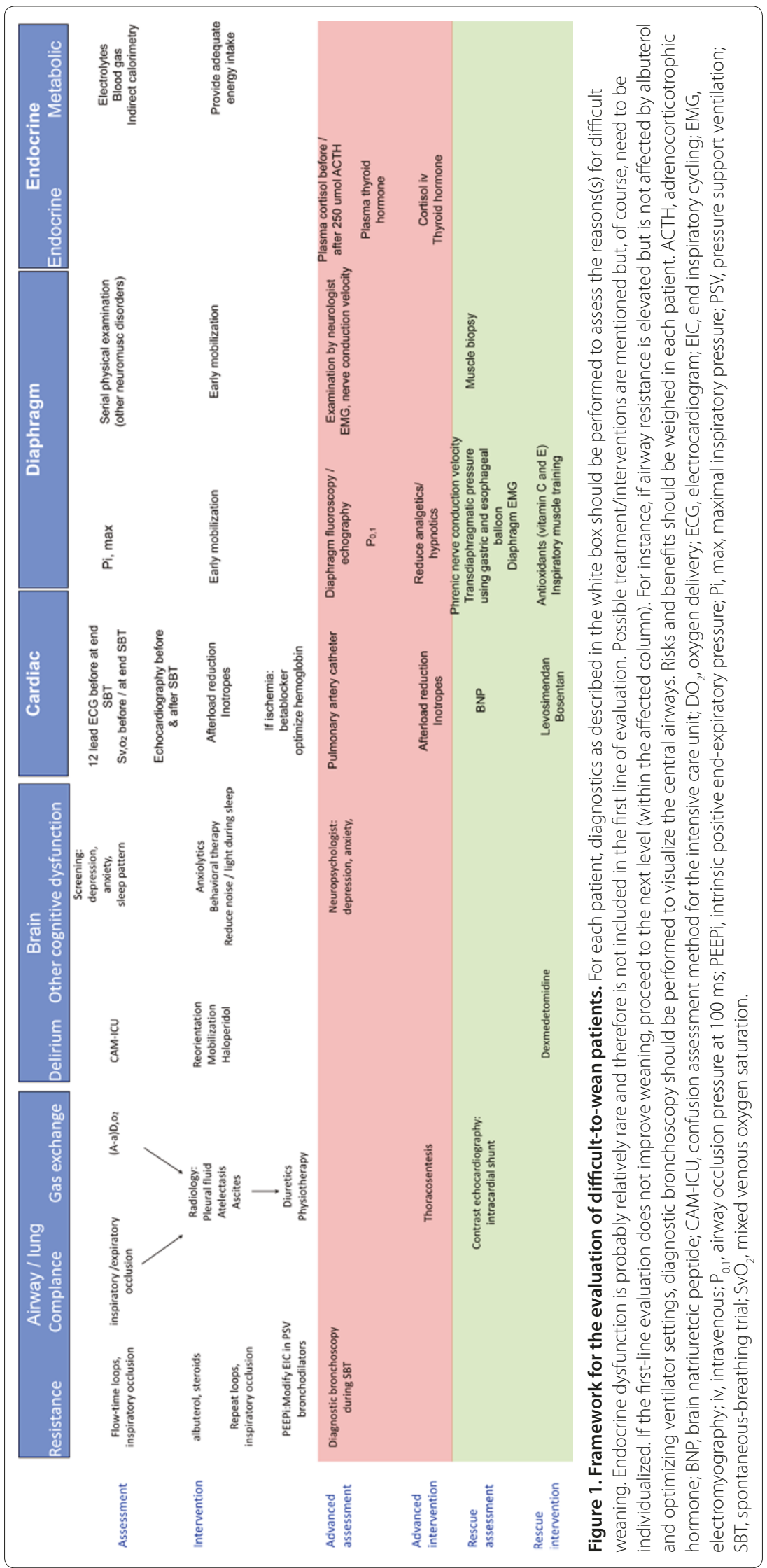


Table 1. Factors affecting respiratory mechanics

\begin{tabular}{lc}
\hline Increased airway resistance & Reduced compliance \\
\hline Tube (small diameter, sputum retention) & Chest wall \\
Central airways & Edema \\
Tracheostomy malposition & Elevated abdominal pressure \\
Sputum plug & Pleural fluid and ascites \\
Corpus alienum (after trauma) & Obesity \\
Tracheomalacia or tracheal stenosis & Lung \\
Small airways & Intrinsic positive end-expiratory pressure \\
Asthma and chronic obstructive pulmonary disease & Alveolar filling (edema, pus, and collapse) \\
Acute respiratory distress syndrome & Pneumonia \\
& Interstitial lung disease and fibrosis
\end{tabular}

failure. The most prevalent causes for impaired mechanics are summarized in Table 1.

\section{Resistance in weaning}

Resistance of the upper airway should be considered in difficult weaning. Rumbak and colleagues [7] found that tracheal obstruction caused by tracheal injury may contribute to weaning failure in patients who were on invasive mechanical ventilation for more than 4 weeks. Tracheal injury includes tracheal stenosis, tracheomalacia, and granulation tissue formation. In intubated patients, the endotracheal tube could increase airway resistance. Indeed, resistance of an endotracheal tube removed from a patient is significantly higher than the resistance of a new tube when tested in a laboratory setting and this is due to contamination of the tube with airway secretions [8]. No correlation between the duration intubation and the resistance of the tube was found. However, in general, it is a misconception that, after extubation, upper airway resistance decreases. In fact, the work of breathing in patients mechanically ventilated for \pm 5.5 days increased after extubation, and this increase was probably due to edema of the upper airways [9].

Increased resistance of the small airways is a characteristic of chronic obstructive pulmonary disease (COPD) and asthma but has been demonstrated in acute respiratory distress syndrome (ARDS), and this latter increase was due to edema of bronchial walls. Vassilakopoulos and colleagues [10] showed, in a heterogeneous group of patients, that airway resistance is significantly higher when failing a weaning trial compared with a successful trial in these same patients. Jubran and Tobin [11] found that, in COPD patients failing a spontaneous-breathing trial, airway resistance significantly increases during this trial $\left(9 \pm 2 \mathrm{~cm} \mathrm{H}_{2} \mathrm{O}\right.$ up to $\left.15 \pm 2 \mathrm{~cm} \mathrm{H}_{2} \mathrm{O} ; P<0.05\right)$, whereas in weaning-success patients, airway resistance did not increase significantly. These studies show that increased airway resistance may contribute to weaning failure.
Increased airway resistance is associated with the development of intrinsic positive end-expiratory pressure (PEEPi). PEEPi develops if expiratory time is shorter than the time needed to empty the lungs to the elastic equilibrium volume of the total respiratory system. Accordingly, PEEPi may develop because of increased flow resistance, expiratory flow limitation, high breathing frequency, and loss of elastic recoil of the lung. Indeed, in COPD patients with weaning failure, PEEPi is higher compared with those successfully weaned [11]. PEEPi acts as an inspiratory threshold before inspiratory flow can be generated and result in elevated work of breathing. In addition, pulmonary hyperinflation resulting from PEEPi places the diaphragm at a suboptimal position on the length-tension curve, impairing the ability to generate negative pressure. Moreover, PEEPi is associated with patient-ventilator asynchrony and, in particular, with ineffective triggering (inspiratory effort without ventilator support). Recently, de Wit and colleagues [12] showed that, in patients with a high incidence of ineffective triggering ( $>10 \%$ of all breaths) (as derived from ventilator waveform tracings), duration of mechanical ventilation is significantly longer compared with patients with a lower incidence of ineffective triggering. Although the causes for ineffective triggering are unknown in this study, it demonstrates the clinical relevance of patient-ventilator asynchrony. Measurement of airway resistance and PEEPi may help clinicians to understand the reason for failed weaning.

\section{Resistance: diagnostic approach}

Flexible bronchoscopy is the gold standard for diagnosing upper airway disease. Patients should be disconnected from the ventilator during bronchoscopy so that the presence of tracheomalacia can be assessed. Tracheomalacia may be treated with (nocturnal) non-invasive ventilation or placement of endotracheal stents [7]. Management of the other causes for central airways obstruction is usually evident but is complex in nature. 


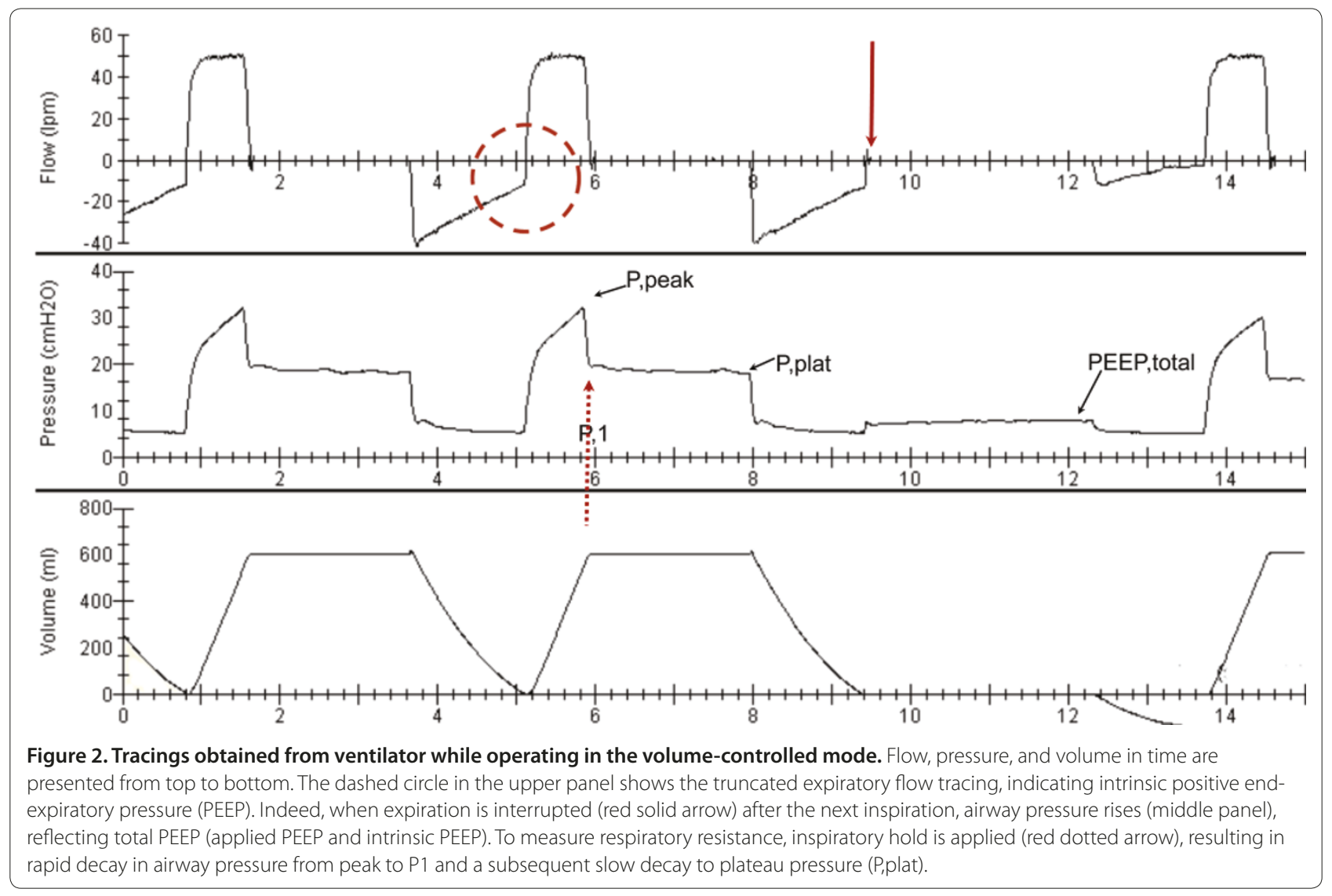

The flow-time and pressure-time loops provide a qualitative assessment of the presence of increased airway resistance and PEEPi (Figure 2). When ventilating with a constant flow, a more quantitative assessment of total airway resistance can be obtained by measuring peak pressure, plateau pressure, and inspiratory flow:

$$
\mathrm{R}, \mathrm{aw}=\left(\mathrm{P}_{\text {peak }}-\mathrm{P}_{\text {plat }}\right) / \text { flow }
$$

(normal is less than $5 \mathrm{~cm} \mathrm{H}_{2} \mathrm{O} / \mathrm{L}$ per second).

PEEPi is obtained by subtracting PEEP ${ }_{\text {appl }}$ from PEEP ${ }_{\text {tot }}$. Unfortunately, this technique is seldom satisfactory in spontaneously breathing patients. In those patients, the only way that PEEPi can be measured adequately is by using an esophageal balloon.

\section{Resistance: therapeutic strategies}

In COPD patients being weaned with pressure support ventilation, appropriate setting of the cycle-off criterion is of importance to limit PEEPi and the work of breathing, as demonstrated by Chiumello and colleagues [13]. Changing the cycling-off criterion from 5\% to $40 \%$ significantly reduced PEEPi and the work of breathing. These effects were most prominent at low levels of pressure support [13]. Applied PEEP may reduce inspiratory work of breathing imposed by PEEPi [14]. Applied PEEP should match the level of PEEPi, as estimated by the expiratory occlusion technique.

Patients with asthma and COPD should be treated optimally to reduce bronchoconstriction. The effect of bronchodilators in patients without a history of COPD has not been tested, but if airway resistance appears elevated, latent obstructive airway disease may be present. Attention should be paid to the optimal delivery of inhaled medications as this will greatly influence its effect [15]. Clinical studies have shown that, in patients with COPD, the bronchodilating effect does not further increase after four doses of $100 \mu \mathrm{g}$ of albuterol via metered dose inhaler. The effect of $400 \mu \mathrm{g}$ of albuterol lasted for at least 60 minutes. The frequency of administration depends on the severity of bronchoconstriction and its clinical effect. The effect of the long-acting beta- 2 agonist salmeterol (four doses of $25 \mu \mathrm{g}$ ) lasts for at least 6 hours [16]. However, it should be noted that the maximal bronchodilating effect of salmeterol is achieved after more than 30 minutes and therefore is less suitable in the acute setting. As much more experience is available for albuterol in mechanically ventilated patients, it remains the beta- 2 agonist of choice. 


\section{Compliance}

Respiratory compliance is determined by the compliance of the chest wall and lungs (Table 1). In patients with ARDS, compliance was significantly lower at the time of weaning failure compared with weaning success [10]. The static compliance of the respiratory system can be calculated after measuring inspiratory and expiratory plateau pressure and tidal volume (Figure 2):

compliance respiratory system $=\mathrm{TV} /\left(\mathrm{P}_{\text {plat }}-\mathrm{PEEP}_{\text {tot }}\right)$ (normal is 60 to $100 \mathrm{~mL} / \mathrm{cm} \mathrm{H}_{2} \mathrm{O}$ ). Optimizing compliance by reducing edema of the lung and chest wall, resolving atelectasis and thoracocentesis, and removing ascites may facilitate weaning.

\section{Gas exchange}

Most weaning patients still have considerable disturbances in gas exchange at the time of weaning and may develop hypoxemia or hypercapnia or both during a spontaneous-breathing trial [17]. Weaning-failure patients are frequently unable to increase minute ventilation in response to high arterial partial pressure of carbon dioxide $\left(\mathrm{PaCO}_{2}\right)$ because of respiratory muscle weakness, altered respiratory mechanics, and so on. In these patients, it is important to limit instrumental dead space (for instance, resulting from heat and moisture exchangers [18]) as much as possible.

\section{Brain dysfunction}

Delirium and depression in weaning

Brain dysfunction in difficult-to-wean patients is related mostly to delirium. Only one paper specifically studied the role of delirium in weaning, and the paper showed that impaired cognitive function was associated with a more than fourfold higher risk of failed extubation [19]. Other psychological disturbances, such as anxiety and depression, may interfere with successful weaning [20]. Sleep disruption frequently occurs in intensive care unit (ICU) patients, but no data showing the effects of disturbed sleep architecture on weaning are available.

\section{Diagnostic approach}

The confusion assessment method for ICU (CAM-ICU) is a well-validated screening tool for delirium in mechanically ventilated patients [21] and is available in numerous languages, but other screening tools have been validated as well [22]. Diagnosing other cognitive disorders in the ICU is best performed by psychologists or psychiatrists. In general wards, reducing risk factors for delirium reduces the incidence of delirium [23]. Midazolam is considered a risk factor for the development of delirium [24]. A recent multicenter trial indicated that sedation with dexmedetomidine reduced the incidence of delirium and reduced the duration of mechanical ventilation compared with sedation with midazolam [25].

\section{Therapeutic strategies}

High levels of sedatives are associated with increased time spent on the ventilator. A daily wakeup call and, if appropriate, subsequent spontaneous-breathing trials are associated with reduced time spent on the ventilator [26]. The role of sedatives in failed-spontaneous breathing trials or failed extubation is less clear. Depression is associated with weaning failure in patients admitted to a long-term weaning facility [27], and preliminary data suggest that pharmacological treatment of depression favors weaning from mechanical ventilation [20]. Sleep may be improved by limiting noise and light during sleep hours and adequately treating pain/discomfort. The effect of ventilator mode on sleep quality has been a subject of discussion [28,29], and differences in outcome are probably related to the level of pressure support.

\section{Cardiac dysfunction}

The transition from mechanical ventilation to spontaneous breathing imposes an additional load on the cardiovascular system because of intrathoracic pressure changes, which affect ventricular preload and afterload and increased oxygen consumption by the respiratory muscles.

\section{Cardiac function during weaning}

In patients with COPD but without cardiac disease, weaning was associated with a significant reduction in left ventricle ejection fraction and this reduction was probably due to increased left ventricular afterload [30]. Several studies have specifically investigated the effects of weaning with spontaneous-breathing trials on cardiac performance. In patients with $\mathrm{COPD}\left(\mathrm{FEV}_{1}\right.$ [forced expiratory volume in 1 second] $1.0 \pm 0.2 \mathrm{~L}$ ) but without a history of cardiac disease, weaning was associated with a reduction in left ventricle ejection fraction $(54 \% \pm 12 \%$ versus $47 \% \pm 13 \%$ during mechanical ventilation and spontaneous breathing, respectively; $P<0.01$ ) [30]. As the authors did not find evidence for myocardial ischemia when using technetium radionuclide angiography in these patients, it was proposed that increased left ventricle afterload imposed by disconnection from the ventilator caused the reduction in left ventricle ejection fraction. Moreover, in difficult-weaning patients with COPD and a history of heart disease, spontaneousbreathing trials resulted in elevated pulmonary artery occlusion pressure and left ventricular end diastolic pressure, suggesting reduced ventricular compliance [31]. Elevated left ventricular end diastolic pressure during weaning may induce pulmonary and bronchial wall edema and thus increase the work of breathing.

In a heterogeneous group of patients with a failedweaning trial, a progressive decline in mixed venous oxygen saturation $\left(\mathrm{SvO}_{2}\right)$ was found [32]. The decrease in $\mathrm{SvO}_{2}$ resulted from the inability to improve cardiac 
output and therefore oxygen transport. Increased afterloads of both the right ventricle and left ventricle were found in these patients.

Brain natriuretcic peptide (BNP) is a hormone released from the myocardium upon stretch. In patients with failed-spontaneous breathing trials and in failedextubation patients, changes in BNP are significantly higher than in patients with successful extubation [33]. This response of BNP does support a role for cardiac failure in selected difficult-weaning patients.

\section{Diagnostic approach}

The first step to assess cardiac dysfunction as a cause for weaning failure is electrocardiography at the final stages of the weaning trial to detect ischemia. Subsequently, $\mathrm{SvO}_{2}$ could be used as a screening tool for cardiac dysfunction in difficult weaning. It should be noted that reduction in $\mathrm{SvO}_{2}$ is the normal response to increased loading. In healthy subjects performing moderate exercise, $\mathrm{SvO}_{2}$ decreases below 50\% [34]. Accordingly, a decrease in $\mathrm{SvO}_{2}$ should not be regarded as a sign of cardiac failure. On the other hand, in weaning-failure patients, without a reduction in $\mathrm{SvO}_{2}$, cardiac failure is highly unlikely but rather is the result of hypoventilation, lack of motivation, or cognitive dysfunction. Accordingly, in patients who do exhibit a decrease in $\mathrm{SvO}_{2}$ during failed weaning, cardiac failure may play a role and measurement of pulmonary artery occlusion pressure and cardiac output by means of a Swan-Ganz catheter [35] or echocardiography [36] must be considered.

\section{Treatment strategies}

In difficult-to-wean patients with evidence of cardiac failure, afterload reduction and ultimately the use of inotropes must be considered. Notably, amelioration of pulmonary mechanics will reduce left ventricle afterload. No studies have compared the different classes of inotropes in these patients. Levosimendan is a new inotropic used in the treatment of cardiac failure [37]. One of the mechanisms of action is enhanced calcium sensitivity of the cardiac contractile proteins, resulting in elevated pressure generation. In a preliminary study [38], levosimendan was tested in 12 patients who had heart failure (left ventricular ejection fraction of $28 \% \pm 5 \%$ ) and who were difficult to wean from mechanical ventilation (ventilator dependency for more than 10 days). Within 51 hours of levosimendan treatment, 7 of the 12 patients could be weaned from the ventilator. The other 5 patients could not be weaned at all and died in the ICU. Though promising, levosimendan has not been tested in placebocontrolled trials or directly compared with the older inotropes in weaning-failure patients. Interestingly, it was recently shown that levosimendan improves contractility of human diaphragm muscle fibers as well [39].

\section{Diaphragm/respiratory muscle function}

Initiating a spontaneous-weaning trial puts an acute load on the inspiratory muscles. The elevated load is imposed on a weakened respiratory muscle pump. When considering the inspiratory muscles as a cause for weaning failure, it should be kept in mind that dysfunction of the ventilatory pump may result from a lesion anywhere between the afferent chemo-receptors of the respiratory centers and the contractile proteins.

\section{Drive, weakness, and fatigue}

Impaired respiratory drive is an uncommon cause of weaning failure. In fact, in most weaning-failure patients, respiratory drive is increased [17]. Occasionally, clinically relevant diaphragm dysfunction results from damage to the phrenic nerve(s). The most frequent disorder affecting the phrenic nerves is critical illness polyneuropathy. As biopsy studies have shown that critical illness polyneuropathy and critical illness myopathy often coexist [40], the term 'ICU-acquired weakness' has gained popularity. There is convincing evidence that contractility of the respiratory muscles is impaired in mechanically ventilated patients. Laghi and colleagues [41] found that, in a heterogeneous group of mechanically ventilated patients ( \pm 29 days), transdiaphragmatic pressure obtained after magnetic stimulation of the phrenic nerves was only approximately $35 \%$ compared with healthy subjects [42]. Levine and colleagues [43] found profound muscle fiber atrophy accompanied by activation of the proteolytic ubiquitin-proteasome pathway in the diaphragm of patients mechanically ventilated for 18 to 96 hours. Thus, there is little discussion of whether respiratory muscles are weak in ICU patients, but the development of muscle fatigue after a failed-weaning trial is the subject of debate. Laghi and colleagues [41] assessed diaphragm force before and 30 minutes after a failed-weaning trial. Surprisingly, these patients did not develop inspiratory muscle fatigue. Possible explanations for these unexpected findings include early reconnection of the patient to the ventilator, recruitment of other inspiratory muscles, or muscle recovery from fatigue within 30 minutes after the weaning trial. Although ICU-acquired weakness is the most frequent neurological disorder in the ICU, other neurological disorders may be associated with difficult weaning (reviewed in [44]).

\section{Diagnostic approach}

The diagnostic approach of diaphragm dysfunction is sophisticated, and an in-depth neurological examination should be performed by a neurologist. The most frequently used test to evaluate respiratory drive in mechanically ventilated or spontaneously breathing patients is the airway occlusion pressure at $100 \mathrm{~ms}\left(\mathrm{P}_{0.1}\right)$. To this end, the inspiratory limb of the ventilator is occluded and 
the drop in airway pressure is continuously monitored. In normal subjects, $\mathrm{P}_{0.1}$ is about 0.5 to $1.5 \mathrm{~cm} \mathrm{H}_{2} \mathrm{O}$. It should be noted that $\mathrm{P}_{0.1}$ depends not only on respiratory drive but also on inspiratory muscle capacity. Accordingly, a reduced $\mathrm{P}_{0.1}$ is not a very specific sign of impaired drive, but in patients with normal/high $\mathrm{P}_{0.1}$, impaired drive is highly unlikely.

Generalized skeletal muscle weakness will guide the clinician to respiratory muscle weakness but does not prove inspiratory muscle weakness, and vice versa. A global assessment of inspiratory muscle function can be obtained by measuring maximal inspiratory pressure. Lower limits for maximal inspiratory pressure in healthy subjects younger than 65 years old are $-75 \mathrm{~cm} \mathrm{H}_{2} \mathrm{O}$ in men and $-50 \mathrm{~cm} \mathrm{H}_{2} \mathrm{O}$ in women [45]. Values that are more negative virtually exclude significant inspiratory muscle weakness (good negative predictive value). Values that are less negative do not prove muscle weakness (poor positive predictive value), as this method depends on cooperation and lung volume. Accordingly, maximal inspiratory pressure may be useful in evaluating the differential diagnosis of difficult weaning. As this test does not evaluate the endurance of the inspiratory muscles, the value of maximal inspiratory pressure as a weaning predictor is much more controversial [46].

The definite diagnosis of respiratory muscle fatigue after a trial of spontaneous breathing is not feasible in routine clinical care. The development of hypercapnia during a weaning trial is not a very specific finding, as hypercapnia may result from causes other than muscle fatigue, such as central hypoventilation and rapid shallow breathing. The absence of hypercapnia in a weaningfailure patient virtually excludes inspiratory muscle fatigue.

\section{Treatment strategies \\ I. Mechanical ventilation is a double-edged sword for the respiratory muscles}

Unloading prevents the development of fatigue, but inactivity is associated with the development of weakness. Very few studies have assessed the effect of inspiratory muscle training on muscle strength and in particular on clinical outcome such as duration of ventilatory assist. In an observational study, 10 difficultto-wean patients (mechanical ventilation for $34 \pm 31$ days before the start of the study) were subjected to inspiratory muscle training with a pressure threshold training device [47]. Training bouts consisted of three to five sets of six inhalation maneuvers through the device, 5 to 7 times a week. In $44 \pm 43$ days, inspiratory pressure could be increased from $7 \pm 3 \mathrm{~cm} \mathrm{H}_{2} \mathrm{O}$ at inclusion up to $18 \pm 7 \mathrm{~cm}$ $\mathrm{H}_{2} \mathrm{O}$ at the time of successful weaning. It should be noted that this is a small uncontrolled study and the training intensity was set at rather subjective criteria. However, from a physiological point of view, it seems reasonable to train the inspiratory muscles, as part of a generalized training program [48], in patients with inspiratory muscle weakness and prolonged weaning from mechanical ventilation. When considering a training schedule, clinicians should keep in mind that the diaphragm operates mostly at its submaximal force level. Therefore, when the clinician decides that inspiratory muscle training may facilitate weaning from mechanical ventilation, from a physiological point of view, an endurance training strategy is most appropriate.

\section{Antioxidants modulate respiratory muscle function in healthy subjects}

In a large, randomized, non-blinded trial, surgical ICU patients received the antioxidants alpha-tocopherol and ascorbic acid or only standard care from ICU admission until discharge [49]. Antioxidant supplementation was associated with a reduction in ventilator-dependent days from 4.6 to $3.7(P<0.05)$. Further trials are needed before antioxidant treatment can be recommended.

\section{Effects of tight glycemic control on clinically relevant outcome parameters}

The effects of tight glycemic control on clinically relevant outcome parameters (mortality and days of mechanical ventilation) in critically ill patients are complex and well beyond the scope of this review. Notably, in a recent large prospective multicenter study [50], intensive glycemic control did not affect the duration of mechanical ventilation. Although that study did not investigate the prevalence of neuropathy and myopathy, the clinical relevance of such findings would be controversial as tight glycemic control did not favor weaning and reduced survival in this trial.

\section{Effect of growth hormone treatment}

The effect of growth hormone treatment (0.07 to $0.13 \mathrm{mg} / \mathrm{kg}$ of body weight per day) has been reported in two parallel studies published in 1999 [51]. Growth hormone treatment is associated with increased mortality (39\% versus $20 \%$ in the Finnish study and $44 \%$ versus $18 \%$ in the European study). In addition, growth hormone increased time spent on the ventilator. However, the successful use of growth hormone supplementation in ICU patients who are more chronic has been described [52]. Future studies are needed to address this issue, but today the safety of growth hormone supplementation in weaning patients is unknown.

\section{Endocrine and metabolic dysfunction}

The role of endocrine disorders in difficult weaning has gained little interest in the literature. Huang and Lin [53] found that, in 93 selected difficult-to-wean patients, 70 
fulfilled criteria for adrenal insufficiency. Cortisol supplementation in these patients reduced duration of weaning compared with placebo $(3.4 \pm 2.3$ days versus $6.5 \pm 4.7$ days, respectively; $P<0.05$ ). The pathophysiological mechanisms for improved clinical outcome in these cortisol-supplemented patients are, however, unknown.

For a variety of reasons, including decreased central drive [54] and respiratory muscle weakness [55], hypothyroidism may delay weaning from mechanical ventilation. In a retrospective study [56], 3\% of patients (4/140) admitted to a long-term weaning facility were diagnosed with new-onset hypothyroidism. After thyroid hormone supplementation, three patients could be weaned from mechanical ventilation. Although the effect of thyroid hormone supplementation in difficult-weaning patients is anecdotal, it is reasonable in weaning-failure patients with a laboratory diagnosis of hypothyroidism.

Malnutrition frequently occurs in mechanically ventilated patients and is associated with poor prognosis [57] but also with reduced muscle mass and as such contributes to difficult weaning. Nutritional status should be evaluated by determining body mass index, plasma albumin concentration, and nitrogen balance [58]. Ideally, energetic needs should be determined by indirect calorimetry to prevent under- and overfeeding.

Electrolyte abnormalities, including very low plasma levels of phosphate and magnesium, have been shown to affect skeletal muscle function. Although these should be corrected in difficult-weaning patients, no studies have investigated the role electrolyte abnormalities in weaning failure. Other metabolic disturbances that increase the work of breathing and that therefore may be associated with difficult weaning include metabolic acidosis and fever.

\section{Conclusions}

As outlined, the reasons for failing a weaning trial are diverse. When a patient does not pass a weaning trial, structural evaluation could help to identify factors that played a role in that specific patient. Our opinion-based 'ABC' algorithm could be helpful. It should be noted that the algorithm has several loose ends as our understanding of weaning failure is far from complete.

\section{Abbreviations}

ARDS, acute respiratory distress syndrome; BNP, brain natriuretcic peptide; COPD, chronic obstructive pulmonary disease; ICU, intensive care unit; $\mathrm{P}_{0.1{ }^{\prime}}$ airway occlusion pressure at $100 \mathrm{~ms}$; PEEPi, intrinsic positive end-expiratory pressure; $\mathrm{SvO}_{2}$, mixed venous oxygen saturation.

\section{Competing interests}

The authors declare that they have no competing interests.

Published: 8 December 2010

\section{References}

1. Boles JM, Bion J, Connors A, Herridge M, Marsh B, Melot C, Pearl R, Silverman $\mathrm{H}$, Stanchina M, Vieillard-Baron A, Welte T: Weaning from mechanical ventilation. Eur Respir J 2007, 29:1033-1056.
2. Tobin MJ, Jubran A: Weaning from mechanical ventilation. In Principles and Practice of Mechanical Ventilation. 2nd edition. Edited by Tobin MJ. New York: McGraw-Hill; 2006:1185-1220.

3. Esteban A, Frutos F, Tobin MJ, Alia I, Solsona JF, Valverdu I, Fernandez R, de la Cal MA, Benito S, Tomas R: A comparison of four methods of weaning patients from mechanical ventilation. Spanish Lung Failure Collaborative Group. N Engl J Med 1995, 332:345-350.

4. Vitacca M, Vianello A, Colombo D, Clini E, Porta R, Bianchi L, Arcaro G, Vitale G, Guffanti E, Lo Coco A, Ambrosino N: Comparison of two methods for weaning patients with chronic obstructive pulmonary disease requiring mechanical ventilation for more than 15 days. Am J Respir Crit Care Med 2001, 164:225-230.

5. Brochard L, Rauss A, Benito S, Conti G, Mancebo J, Rekik N, Gasparetto A Lemaire F: Comparison of three methods of gradual withdrawal from ventilatory support during weaning from mechanical ventilation. Am J Respir Crit Care Med 1994, 150:896-903.

6. Carley S, Driscoll P: Trauma education. Resuscitation 2001, 48:47-56.

7. Rumbak MJ, Walsh FW, Anderson WM, Rolfe MW, Solomon DA: Significant tracheal obstruction causing failure to wean in patients requiring prolonged mechanical ventilation: a forgotten complication of long-term mechanical ventilation. Chest 1999, 115:1092-1095.

8. Wilson AM, Gray DM, Thomas JG: Increases in endotracheal tube resistance are unpredictable relative to duration of intubation. Chest 2009, 136:1006-1013.

9. Ishaaya AM, Nathan SD, Belman MJ: Work of breathing after extubation. Chest 1995, 107:204-209.

10. Vassilakopoulos T, Zakynthinos S, Roussos C: The tension-time index and the frequency/tidal volume ratio are the major pathophysiologic determinants of weaning failure and success. Am J Respir Crit Care Med 1998, 158:378-385

11. Jubran A, Tobin MJ: Pathophysiologic basis of acute respiratory distress in patients who fail a trial of weaning from mechanical ventilation. Am J Respir Crit Care Med 1997, 155:906-915.

12. de Wit M, Miller KB, Green DA, Ostman HE, Gennings C, Epstein SK: Ineffective triggering predicts increased duration of mechanical ventilation. Crit Care Med 2009, 37:2740-2745.

13. Chiumello D, Polli F, Tallarini F, Chierichetti M, Motta G, Azzari S, Colombo R, Rech R, Pelosi P, Raimondi F, Gattinoni L: Effect of different cycling-off criteria and positive end-expiratory pressure during pressure support ventilation in patients with chronic obstructive pulmonary disease. Crit Care Med 2007, 35:2547-2552.

14. Guerin C, Milic-Emili J, Fournier G: Effect of PEEP on work of breathing in mechanically ventilated COPD patients. Intensive Care Med 2000, 26:1207-1214.

15. Georgopoulos D, Mouloudi E, Kondili E, Klimathianaki M: Bronchodilator delivery with metered-dose inhaler during mechanical ventilation. Crit Care 2000, 4:227-234.

16. Malliotakis P, Linardakis M, Gavriilidis G, Georgopoulos D: Duration of salmeterol-induced bronchodilation in mechanically ventilated chronic obstructive pulmonary disease patients: a prospective clinical study. Crit Care 2008, 12:R140.

17. Tobin MJ, Perez W, Guenther SM, Semmes BJ, Mador MJ, Allen SJ, Lodato RF, Dantzker DR: The pattern of breathing during successful and unsuccessful trials of weaning from mechanical ventilation. Am Rev Respir Dis 1986, 134:1111-1118.

18. Le Bourdellès G, Mier L, Fiquet B, Djedaïni K, Saumon G, Coste F, Dreyfuss D: Comparison of the effects of heat and moisture exchangers and heated humidifiers on ventilation and gas exchange during weaning trials from mechanical ventilation. Chest 1996, 110:1294-1298.

19. Salam A, Tilluckdharry L, Moateng-Adjepong Y, Manthous CA: Neurologic status, cough, secretions and extubation outcomes. Intensive Care Med 2004, 30:1334-1339.

20. Rothenhäusler HB, Ehrentraut $\mathrm{S}$, von Degenfeld G, Weis M, Tichy M, Kilger E, Stoll C, Schelling G, Kapfhammer HP: Treatment of depression with methylphenidate in patients difficult to wean from mechanical ventilation in the intensive care unit. J Clin Psychiatry 2000, 61:750-755.

21. Ely EW, Inouye SK, Bernard GR, Gordon S, Francis J, May L, Truman B, Speroff T, Gautam S, Margolin R, Hart RP, Dittus R: Delirium in mechanically ventilated patients: validity and reliability of the confusion assessment method for the intensive care unit (CAM-ICU). JAMA 2001, 286:2703-2710.

22. Bergeron N, Dubois MJ, Dumont M, Dial S, Skrobik Y: Intensive Care Delirium 
Screening Checklist: evaluation of a new screening tool. Intensive Care Med 2001, 27:859-864.

23. Inouye SK, Bogardus ST Jr., Charpentier PA, Leo-Summers L, Acampora D, Holford TR, Cooney LM Jr.: A multicomponent intervention to prevent delirium in hospitalized older patients. N Eng/ J Med 1999, 340:669-676.

24. Marcantonio ER, Goldman L, Mangione CM, Ludwig LE, Muraca B, Haslauer CM, Donaldson MC, Whittemore AD, Sugarbaker DJ, Poss R: A clinical prediction rule for delirium after elective noncardiac surgery. JAMA 1994, 271:134-139.

25. Riker RR, Shehabi Y, Bokesch PM, Ceraso D, Wisemandle W, Koura F, Whitten P, Margolis BD, Byrne DW, Ely EW, Rocha MG: Dexmedetomidine vs midazolam for sedation of critically ill patients: a randomized trial. JAMA 2009, 301:489-499.

26. Girard TD, Kress JP, Fuchs BD, Thomason JW, Schweickert WD, Pun BT, Taichman DB, Dunn JG, Pohlman AS, Kinniry PA, Jackson JC, Canonico AE, Light RW, Shintani AK, Thompson JL, Gordon SM, Hall JB, Dittus RS, Bernard GR, Ely EW: Efficacy and safety of a paired sedation and ventilator weaning protocol for mechanically ventilated patients in intensive care (Awakening and Breathing Controlled trial): a randomised controlled trial. Lancet 2008, 371:126-134.

27. Jubran A, Lawm G, Kelly J, Duffner LA, Gungor G, Collins EG, Lanuza DM, Hoffman LA, Tobin MJ: Depressive disorders during weaning from prolonged mechanical ventilation. Intensive Care Med 2010, 36:828-835.

28. Cabello B, Thille AW, Drouot X, Galia F, Mancebo J, d'Ortho MP, Brochard L: Sleep quality in mechanically ventilated patients: comparison of three ventilatory modes. Crit Care Med 2008, 36:1749-1755.

29. Parthasarathy S, Tobin MJ: Effect of ventilator mode on sleep quality in critically ill patients. Am J Respir Crit Care Med 2002, 166:1423-1429.

30. Richard C, Teboul JL, Archambaud F, Hebert JL, Michaut P, Auzepy P: Left ventricular function during weaning of patients with chronic obstructive pulmonary disease. Intensive Care Med 1994, 20:181-186.

31. Lemaire F, Teboul JL, Cinotti L, Giotto G, Abrouk F, Steg G, Quin-Mavier I, Zapol WM: Acute left ventricular dysfunction during unsuccessful weaning from mechanical ventilation. Anesthesiology 1988, 69:171-179.

32. Jubran A, Mathru M, Dries D, Tobin MJ: Continuous recordings of mixed venous oxygen saturation during weaning from mechanical ventilation and the ramifications thereof. Am J Respir Crit Care Med 1998, 158:1763-1769.

33. Chien JY, Lin MS, Huang YC, Chien YF, Yu CJ, Yang PC: Changes in B-type natriuretic peptide improve weaning outcome predicted by spontaneous breathing trial. Crit Care Med 2008, 36:1421-1426.

34. Casaburi R, Daly J, Hansen JE, Effros RM: Abrupt changes in mixed venous blood gas composition after the onset of exercise. J Appl Physiol 1989, 67:1106-1112

35. Zakynthinos S, Routsi C, Vassilakopoulos T, Kaltsas P, Zakynthinos E, Kazi D, Roussos C: Differential cardiovascular responses during weaning failure: effects on tissue oxygenation and lactate. Intensive Care Med 2005, 31:1634-1642

36. Jardin F, Vieillard-Baron A: Weaning failure from cardiovascular origin. Intensive Care Med 2006, 32:937.

37. Mebazaa A, Nieminen MS, Packer M, Cohen-Solal A, Kleber FX, Pocock SJ, Thakkar R, Padley RJ, Poder P, Kivikko M: Levosimendan vs dobutamine for patients with acute decompensated heart failure: the SURVIVE Randomized Trial. JAMA 2007, 297:1883-1891.

38. Sterba M, Banerjee A, Mudaliar Y: Prospective observational study of levosimendan and weaning of difficult-to-wean ventilator dependent intensive care patients. Crit Care Resusc 2008, 10:182-186.

39. van Hees HW, Dekhuijzen PN, Heunks LM: Levosimendan enhances force generation of diaphragm muscle from patients with chronic obstructive pulmonary disease. Am J Respir Crit Care Med 2009, 179:41-47.

40. Latronico N, Fenzi F, Recupero D, Guarneri B, Tomelleri G, Tonin P, De MG, Antonini L, Rizzuto N, Candiani A: Critical illness myopathy and neuropathy. Lancet 1996, 347:1579-1582.
41. Laghi F, Cattapan SE, Jubran A, Parthasarathy S, Warshawsky P, Choi YS, Tobin $\mathrm{MJ}$ : Is weaning failure caused by low-frequency fatigue of the diaphragm? Am J Respir Crit Care Med 2003, 167:120-127.

42. Mills GH, Kyroussis D, Hamnegard CH, Polkey MI, Green M, Moxham J: Bilateral magnetic stimulation of the phrenic nerves from an anterolateral approach. Am J Respir Crit Care Med 1996, 154:1099-1105.

43. Levine S, Nguyen T, Taylor N, Friscia ME, Budak MT, Rothenberg P, Zhu J, Sachdeva R, Sonnad S, Kaiser LR, Rubinstein NA, Powers SK, Shrager JB: Rapid disuse atrophy of diaphragm fibers in mechanically ventilated humans. N Engl J Med 2008, 358:1327-1335.

44. Dhand UK: Clinical approach to the weak patient in the intensive care unit. Respir Care 2006, 51:1024-1040.

45. Black LF, Hyatt RE: Maximal respiratory pressures: normal values and relationship to age and sex. Am Rev Respir Dis 1969, 99:696-702.

46. Yang KL, Tobin MJ: A prospective study of indexes predicting the outcome of trials of weaning from mechanical ventilation. N Engl J Med 1991, 324:1445-1450.

47. Martin AD, Davenport PD, Franceschi AC, Harman E: Use of inspiratory muscle strength training to facilitate ventilator weaning: a series of 10 consecutive patients. Chest 2002, 122:192-196.

48. Schweickert WD, Pohlman MC, Pohlman AS, Nigos C, Pawlik AJ, Esbrook CL, Spears L, Miller M, Franczyk M, Deprizio D, Schmidt GA, Bowman A, Barr R, McCallister KE, Hall JB, Kress JP: Early physical and occupational therapy in mechanically ventilated, critically ill patients: a randomised controlled trial. Lancet 2009, 373:1874-1882.

49. Travaline JM, Sudarshan S, Roy BG, Cordova F, Leyenson V, Criner J: Effect of $\mathrm{N}$-Acetylcysteine on human diaphragm strength and fatigability. Am J Resp Crit Care Med 1997, 156:1567-1571.

50. Finfer S, Chittock DR, Su SY, Blair D, Foster D, Dhingra V, Bellomo R, Cook D, Dodek P, Henderson WR, Hebert PC, Heritier S, Heyland DK, McArthur C, McDonald E, Mitchell I, Myburgh JA, Norton R, Potter J, Robinson BG, Ronco $\mathrm{JJ}$ : Intensive versus conventional glucose control in critically ill patients. NEngl J Med 2009, 360:1283-1297.

51. Takala J, Ruokonen E, Webster NR, Nielsen MS, Zandstra DF, Vundelinckx G, Hinds CJ: Increased mortality associated with growth hormone treatment in critically ill adults. N Engl J Med 1999, 341:785-792.

52. Taylor BE, Buchman TG: Is there a role for growth hormone therapy in refractory critical illness? Curr Opin Crit Care 2008, 14:438-444.

53. Huang CJ, Lin HC: Association between adrenal insufficiency and ventilator weaning. Am J Respir Crit Care Med 2006, 173:276-280.

54. Ambrosino N, Pacini F, Paggiaro PL, Martino E, Contini V, Turini L, Tarchi M, Vitti P, Bramanti M, Pinchera A: Impaired ventilatory drive in short-term primary hypothyroidism and its reversal by L-triiodothyronine. J Endocrinol Invest 1985, 8:533-536.

55. Martinez FJ, Bermudez-Gomez M, Celli BR: Hypothyroidism. A reversible cause of diaphragmatic dysfunction. Chest 1989, 96:1059-1063.

56. Datta D, Scalise P: Hypothyroidism and failure to wean in patients receiving prolonged mechanical ventilation at a regional weaning center. Chest 2004, 126:1307-1312.

57. Faisy C, Rabbat A, Kouchakji B, Laaban JP: Bioelectrical impedance analysis in estimating nutritional status and outcome of patients with chronic obstructive pulmonary disease and acute respiratory failure. Intensive Care Med 2000, 26:518-525.

58. Mechanick Jl, Brett EM: Nutrition and the chronically critically ill patient. Curr Opin Clin Nutr Metab Care 2005, 8:33-39.

doi:10.1186/cc9296

Cite this article as: Heunks LMA, van der Hoeven JG: Clinical review: The ABC

of weaning failure - a structured approach. Critical Care 2010, 14:245. 